\title{
OS “NOVOS” CONTOS DE FADAS: TRADIÇÃO E INOVAÇÃO EM A BELA E A ADORMECIDA, DE GAIMAN E RIDDELL
}

\author{
Marta Passos Pinheiro* \\ Centro Federal de Educação Tecnológica de Minas Gerais \\ Sabrina Ramos Gomes \\ Centro Federal de Educação Tecnológica de Minas Gerais
}

\begin{abstract}
Resumo
Neste artigo, investigamos a tradição e a inovação na obra A Bela e a Adormecida por meio da análise da construção da narrativa, considerando o importante papel do projeto gráfico e das ilustrações. Dessa forma, abordamos as colaborações entre dois importantes autores britânicos: o escritor Neil Gaiman e o ilustrador Chris Riddell. Como referencial teórico priorizamos os estudos sobre ilustração e projeto gráfico de livros infantis - Nikolajeva e Scott, Moraes, Linden, Ramos -, dialogando com estudos sobre contos de fadas - Betelheim, Coelho, Corso e Corso. Pudemos observar que mesmo não se tratando de um livro ilustrado, de acordo com a concepção inglesa de picturebook, a narrativa é contada não apenas pelo texto escrito, mas também pelas ilustrações e pelo projeto gráfico. O diálogo entre escritor e ilustrador e a liberdade que este teve para apresentar seu ponto de vista foram fundamentais para o sucesso da obra.

Palavras-chave: Contos de Fadas; Ilustração; Projeto Gráfico; Neil Gaiman; Chris Riddell.
\end{abstract}

\begin{abstract}
We investigate in this article tradition and innovation in the book The Sleeper and the Spindle through the analysis of the narrative construction. We also look upon the important role played by the graphic project and illustrations in this book. Thus, we address in our analysis the collaboration between two important British authors: the writer Neil Gaiman and the illustrator Chris Riddell. We prioritize as theoretical reference for this study the research made on illustration and graphical project of children books by Nikolajeva e Scott, Moraes, Linden, Ramos. We also employ the studies of fairy tales by Betelheim, Coelho, Corso e Corso. Taking into consideration that the book cannot be categorized as a picturebook as defined by the British concept, the narrative is not only told by its texts,
\end{abstract}

\footnotetext{
"Graduada em Letras - Português e Literatura pela Universidade do Estado do Rio de Janeiro (1996), mestre em Literatura Brasileira pela Universidade do Estado do Rio de Janeiro (2000), doutora em Educação pela Universidade Federal de Minas Gerais (2006). Atualmente é professora do Departamento de Linguagem e Tecnologia do Centro Federal de Educação Tecnológica de Belo Horizonte (Cefet-MG). Seu e-mail é martapassaro@gmail.com.

${ }^{* *}$ Mestranda em Estudos de Linguagens, no Centro Federal de Educação Tecnológica de Minas Gerais. (CEFETMG).Seu e-mail é sabrinaramosgomes@gmail.com.
} 
but also by its illustrations and graphic project, as highlighted in this essay. The dialogue between writer and illustrator and the freedom that the latter had to present his point of view were the milestone for the success of this book.

Keywords: fairy tales; illustration; graphic project; Neil Gaiman; Chris Riddell.

\section{Considerações Iniciais}

O conto de fadas é reconhecido como gênero que deu origem à literatura infantil, sendo caracterizado não necessariamente pela presença de fadas, mas por um "espaço 'maravilhoso', isto é, fora da realidade concreta", como destaca Coelho (1991, p. 90). Essas narrativas têm como origem os contos orais que circularam durante a Idade Média e que foram adaptados para o público infantil. O francês Charles Perrault é considerado o primeiro compilador dessas histórias, publicando Contos da Mãe Gansa, em 1697, uma coletânea com oito narrativas em versos, cuja autoria, como destaca Coelho (2012), Perrault atribui a seu filho, Pierre Perrault. No século XIX, destacam-se as compilações dos irmãos Jacob e Wilhelm Grimm, na Alemanha, e as de Hans Christian Andersen, na Dinamarca. Este último, além de compilar e adaptar os contos orais, também criou muitas histórias, sendo considerado o patriarca da literatura infantil.

Estudiosos desse gênero literário, em análise psicanalítica, segundo Coelho (1991) as mais frequentes, como as de Bettelheim (1980), Von Franz (1990), Giglio (1991) e Corso e Corso (2006), concebem o conto de fadas como uma forma de expressão de arquétipos do inconsciente coletivo. Para esses pesquisadores, mesmo sofrendo adaptações, essas narrativas apresentam estruturas arquetípicas, sendo, portanto, de alcance universal.

No século XX, destacam-se as adaptações do gênero feitas e amplamente divulgadas pelos Estúdios Disney, que tornaram os contos de fadas conhecidos por todos. Nessas duas décadas do século XXI, chama a atenção a quantidade de adaptações, releituras e recriações dos contos de fadas tradicionais, assim como a quantidade de histórias que dialogam, de várias maneiras, com esses contos. Acreditamos que a existência nesse gênero de uma estrutura arquetípica, com a presença do bem e do mal, do herói e da aventura, faz com que ele seja objeto de muitas releituras e adaptações para outros gêneros e mídias.

Dentre as narrativas produzidas a partir do diálogo com os contos de fadas, encontram-se duas obras escritas pelo autor britânico Neil Gaiman: João e Maria, lançada no Brasil em setembro de 2015 pela editora Intrínseca, traduzida por Augusto Calil, com ilustrações de Lorenzo Mattotti, e A Bela e a Adormecida, lançada no Brasil em novembro de 2015 pela editora Rocco (selo Rocco Jovens Leitores), traduzida por Renata Pettengil, com ilustrações de Chris Riddell. Ambas as obras fazem referência, já no título, a contos de fadas tradicionais, acrescentando novas camadas ao imaginário preexistente desses contos. João e Maria pode ser considerada uma releitura de uma das versões publicadas pelos irmãos Grimm. Já A Bela e a Adormecida, cujo título original é The Sleeper and the Spindle (algo 
como A dorminhoca e o fuso da roca), pode ser considerada uma nova história, com muitas referências aos contos de fadas "Branca de Neve" e "A Bela Adormecida", apresentando, assim, um interessante jogo entre tradição e inovação.

Neste artigo, investigamos a tradição e a inovação na obra A Bela e a Adormecida por meio da análise da construção da narrativa, considerando o importante papel do projeto gráfico e das ilustrações. Dessa forma, abordamos em nossa análise as colaborações, para a produção da obra, entre dois importantes autores britânicos: o escritor Neil Gaiman e o ilustrador Chris Riddell. Consideramos como tradição o diálogo estabelecido com os contos de fadas tradicionais e como inovação o que a obra apresenta de novo, as quebras de expectativas provocadas nos leitores.

A história de Gaiman foi publicada primeiramente, de forma mais simplificada, no livro Rags \& Bones: new twists on timeless tales, editado por Melissa Marr e Tim Pratt e publicado em 2013 pela Little Brown. Trata-se de uma coletânea de contos, baseados em histórias clássicas e contos de fadas, recontados por autores famosos e premiados, como Neil Gaiman, Kami Garcia e Garth Nix. A obra A Bela e a Adormecida, com as ilustrações de Riddell, foi publicada na Grã-Bretanha em 2014, pela Bloomsbury Publishing. No Brasil, foi publicada um ano depois, pela Rocco, que manteve o projeto gráfico original.

Neil Gaiman, autor britânico do texto escrito de A Bela e a Adormecida, nasceu em Portchester, em 1960, e tornou-se conhecido primeiramente por escrever histórias em quadrinhos. A série para adultos Sandman, de sua autoria, foi a primeira série de quadrinho a receber um prêmio literário, o World Fantasy Award. A obra desse autor é fortemente marcada pela influência do Romantismo, principalmente em sua corrente gótica, além da influência da mitologia nórdica e dos contos de fadas.

Chris Riddell, autor britânico das ilustrações de A Bela e a Adormecida, nasceu na Cidade do Cabo, na África do Sul, em 1962, e mudou-se para a Inglaterra ainda criança. É ilustrador e escritor de livros infantis e cartunista político do jornal The Observer. Dentre os inúmeros prêmios que recebeu, estão as medalhas Kate Greenway, em 2001 e 2004, e o Children's Laureate inglês, no biênio de 2015/2017.

Como referencial teórico para este trabalho, priorizamos os estudos sobre ilustração e projeto gráfico de livros infantis desenvolvidos por Nikolajeva e Scott (2011), Moraes (2008), Linden (2011) e Ramos (2013). O projeto gráfico de um livro envolve (ADG, 2012, p. 162) desde "o planejamento das características gráficas e visuais de uma publicação", até "o detalhamento de especificações para a produção gráfica, como formato, papel, processos de composição, impressão e acabamento." Dialogamos também com estudos sobre contos de fadas - Betelheim (1980), Coelho (1991), Corso e Corso (2006). Antes da análise proposta, apresentamos uma breve reflexão sobre a importância das ilustrações para a literatura infantil e juvenil contemporânea.

\section{A importância das ilustrações na literatura infantil e juvenil contemporânea}

O período conhecido como a idade de ouro das ilustrações, no mundo an- 
glo-saxão, é compreendido a partir de meados do século XIX (RAMOS, 2013, p. 56), sendo Alice no País das Maravilhas, de Lewis Carroll, com ilustrações de John Tenniel, publicada em 1865, a obra clássica mais famosa do período. Contudo, o forte diálogo entre ilustração e texto escrito, que vem caracterizando a produção de livos infantis contemporânea, tem como precursor o britânico Randolph Caldecott (1846-1886), nascido em Chester. Ele tem sido apontado como o grande inovador dos livros infantis por propor a construção da narrativa a partir da integração entre ilustração e palavra. Como nos informa Ramos: "Em Hey, Diddle, Diddle (1882) Caldecott demonstrou que a força da ilustração poderia ser equivalente à do texto, tornando-a elemento imprescindível para a compreensão da história." (RAMOS, 2013, p. 60). Caldecott é reconhecido pelo norte-americano Maurice Sendak (1928-2012), em Caldecott \& Co.: Notes on Books and Pictures (1988), como inventor do livro infantil ilustrado moderno.

Esse tipo de produção, que tem em Caldecott um importante precursor, foi desenvolvida, nos países de língua inglesa, a partir da década de 1960, tendo como importante referência Where the wild things are, de Maurice Sendak, publicado nos Estados Unidos em 1963, na Inglaterra em 1968 e no Brasil apenas em 2010, traduzido como Onde vivem os monstros.

Desde as últimas décadas do século XX, observa-se, nos países ocidentais, um aumento da produção de livros voltados para o público infantil e juvenil e uma valorização, principalmente nos livros infantis, da linguagem visual, ou seja, da ilustração e do projeto gráfico (design). Essa valorização certamente foi influenciada também pelas histórias em quadrinhos, que surgiram no ocidente no final do século XIX e foram amplamente divulgadas ao longo do século XX. Nesse tipo de produção, a narrativa é construída a partir do diálogo entre texto escrito e ilustração.

Eisner (1917-2005), renomado quadrinista norte-americano, ressalta a importância das histórias em quadrinhos para o desenvolvimento da leitura visual no século XX: a "leitura visual é uma das habilidades obrigatórias para a comunicação neste século. E as histórias em quadrinhos estão no centro desse fenômeno" (EISNER, 1996, p. 7). Certamente a leitura visual continua sendo uma habilidade fundamental para se viver no século XXI, em sociedades cada vez mais bombardeadas por imagens de todos os tipos. Acreditamos que Neil Gaiman traga para os livros infantis a sensibilidade em relação às imagens proveniente de sua trajetória como autor de histórias em quadrinhos.

Dentre os livros infantis contemporâneos, os que apresentam uma forte interação entre imagem e palavra vêm se destacando, sendo objeto de estudo de muitas pesquisas. Os povos de língua inglesa os denominam picturebook e os de tradição hispânica de livro-álbum (RAMOS, 2013, p. 83). No Brasil, esse tipo de livro vem sendo traduzido como livro ilustrado, em oposição a livro com ilustração, em que as ilustrações, a princípio, se retiradas, não comprometem o sentido da obra. Destacamos a fragilidade dessa concepção, uma vez que as ilustrações muitas vezes contribuem para a construção de significados, mesmo quando o 
texto escrito prescinde delas.

Para a análise da relação entre texto escrito e imagem, várias categorias vêm sendo construídas. Nikolajeva e Scott (2011), ao discutirem a produção teórica sobre o livro ilustrado, apresentam a classificação de diversos pesquisadores, como Joseph H. Schwarcz, Ulla Rhedin, Joanne M. Golden e Perry Nodelman. Nem sempre as diferenças entre livro ilustrado e livro com ilustração vêm sendo consideradas, o que reforça nossa colocação anterior em relação à fragilidade dessa diferenciação. Joseph H. Schwarcz é um dos pesquisadores que "não identifica nenhuma diferença importante entre livro com ilustração e livro ilustrado." (NIKOLAJEVA e SCOTT, 2011, p. 21). Como destacam Nikolajeva e Scott,

ele atenta para a relação quantitativa de texto e imagem em diferentes tipos de livro com ilustração, usando a expressão 'narração verbal-visual' (...). Além disso, ao discutir a função das ilustrações, Schwarcz descreve várias maneiras de cooperação entre palavras e imagens (...). (NIKOLAJEVA e SCOTT, 2011, p. 21)

A análise da função das ilustrações e a proposição de categorias para classificar sua relação com o texto escrito vêm sendo o foco de muitos pesquisadores que se debruçam sobre os livros infantis ilustrados. Contudo, como ressaltam Nikolajeva e Scott, "embora seja instigante, a classificação é insuficiente para descrever o amplo espectro de inter-relações entre palavra e imagem que encontramos nos livros ilustrados" (2011, p. 22).

Linden (2011, p. 120-121) afirma observar apenas três tipos de relações entre texto e imagem: de redundância, de colaboração e de disjunção. De forma resumida, podemos considerar que texto e imagem podem: reproduzir conteúdos idênticos, construir de forma articulada um discurso único ou, o que é mais raro, construir histórias paralelas, em que não haja ponto de convergência entre eles. Ao propor as funções que texto e imagem podem apresentar - repetição, seleção, revelação, completiva, contraponto, amplificação -, Linden (2011, p. 123-125) destaca que primeiramente é fundamental considerar a primazia ou prioridade do texto escrito ou da imagem. Em se tratando de livro ilustrado,

Se o texto é lido antes da imagem e é o principal veiculador da história, ele é prioritário. A imagem, apreendida num segundo momento, pode confirmar ou modificar a mensagem oferecida pelo texto. Inversamente, a imagem pode ser preponderante no âmbito espacial e semântico, e o texto ser lido num segundo momento. (LINDEN, 2011, p. 122)

A pesquisadora utiliza os termos "instância primária" e "instância secundária" para caracterizar o espaço ocupado pelo texto escrito e pelas ilustrações. A diagramação, importante elemento do projeto gráfico de um livro,

desempenha um papel primordial na apreensão prioritária de uma ou outra linguagem. Se a primeira página do livro traz uma mensagem, se essa imagem ocupa o espaço mais importante e se situa acima do texto, sua 
disposição e apresentação influirão também na apreensão. Essa organização espacial, porém, será confirmada ou contrariada dependendo de quem conduz a narrativa ou veicula a mensagem principal. (LINDEN, 2011, p. 122)

Assim sendo, apesar de a narrativa textual, contada pela escrita, ter papel importante na definição de uma instância como primária ou secundária, na medida em que pode confirmar ou contrariar a organização espacial da página, essa organização, que faz parte do projeto gráfico da obra, deve ser considerada como importante elemento de construção de significação. Acreditamos que tanto a diagramação - envolvendo espaço entre linhas e mancha gráfica-, como os demais elementos pertencentes ao design de um livro, como tipografia, formato do livro e papel, devem ser considerados na leitura da narrativa.

Essa importância do design vem caracterizando o livro ilustrado contemporâneo, composto pelo importante tripé, fundamental para se compreender a história narrada: texto escrito, ilustração e projeto gráfico. Sendo assim, podemos considerar o trabalho do designer como uma terceira linguagem. Como defende Odilon Moraes, "o projeto gráfico, sinônimo de design gráfico de um livro, é a proposta particular de uma intenção de leitura a partir de uma junção de textos e imagens em um único objeto" (MORAES, 2008, p. 54).

A importância do diálogo entre essas três linguagens nos livros infantis contemporâneos torna fundamental, para a construção das obras, a colaboração entre escritor, ilustrador e designer. É importante destacar que tem sido cada vez mais comum o projeto gráfico da obra ser feito pela dupla escritor e ilustrador, quando, não raro, por um só autor desempenhando esses três papéis.

A parceria entre Gaiman e Riddell é expressa em várias entrevistas concedidas pelos autores. Riddell relatou em entrevista vinculada no canal HarperTeen, acerca da produção de A Bela e a Adormecida, que é sempre animador receber e-mails de Gaiman, pois geralmente eles contêm algum texto original. Quando Riddell recebeu por e-mail a história de A Bela e a Adormecida, teve certeza que fazer as ilustrações seria algo muito divertido e teria liberdade para mostrar sua visão das histórias. Gaiman, em entrevista, relatou como foi agradável descobrir toda nova gama de personagens acrescentados à história por meio das imagens. Gaiman ressaltou a importância da ilustração nessa obra, destacando como ela proporciona uma experiência diferenciada de leitura: "Eu acho que um livro ricamente ilustrado como esse é simplesmente uma experiência que você não teria só através do texto. Você nunca veria os cogumelos crescendo nos baldes das tiradoras de leite (...)"1 (GAIMAN, 2014).

Pode-se observar que Riddell teve liberdade criativa para acrescentar, nas ilustrações, sua interpretação da narrativa. Apesar de não se tratar de livro ilustrado, de acordo com a definição proposta por muitos teóricos contemporâneos, A Bela e a Adormecida, sem as ilustrações de Riddell, certamente seria uma outra história. 
A Bela e a Adormecida: diálogo entre texto escrito, ilustração e projeto gráfico

A obra A Bela e a Adormecida começa destacando-se por seu projeto gráfico, elaborado conjuntamente pelo autor e pelo ilustrador, como é feito tradicionalmente nos quadrinhos e em muitos livros infantis ilustrados contemporâneos.

O livro apresenta capa dura e sobrecapa em papel vegetal. A capa, preto e branca, contém uma ilustração feita em nanquim de uma jovem de longos cabelos, aparentemente adormecida. A sobrecapa apresenta o nome do livro, dos autores e da editora e é ilustrada com desenhos de roseiras, com algumas flores pretas, grossos caules e espinhos, lembrando trepadeiras, numa tonalidade de ouro velho.

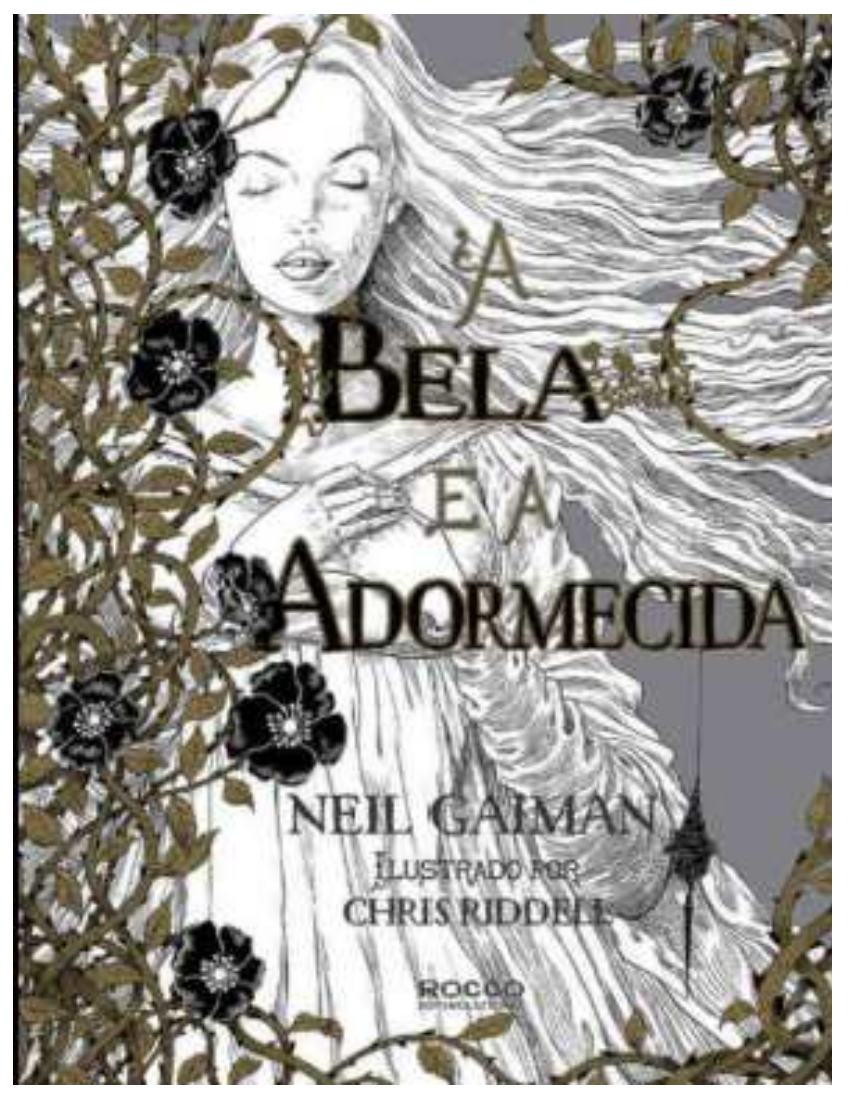

Figura 1 - Capa do livro em Português

Pode-se observar que, pendendo da letra D, da palavra "Adormecida" do título, encontra-se o desenho de um objeto, que o leitor identificará, ao ler a obra, como sendo o fuso do conto A Bela Adormecida. Esse objeto possui uma importante função nesta história, fazendo parte do clímax da narrativa: é por meio dele que a vilã é aniquilada, fazendo com que a mocinha, no corpo de uma velha, entre em um profundo sono rejuvenescedor, como abordaremos mais adiante.

A translucidez do papel da sobrecapa torna aparente a imagem da capa, reforçando o estado "de adormecida" da jovem, já que existe um véu (o papel vege- 
tal) sobre ela, retratando-a aprisionada por uma camada de roseira. Sendo assim, as ilustrações da capa e sobrecapa, associadas às palavras "Bela" e "Adormecida" no título do livro, remetem o leitor ao conto de fadas A Bela Adormecida, no qual uma princesa permaneceu, juntamente aos demais habitantes de seu reino, em sono profundo por cem anos, em um castelo que foi encoberto por uma cerca de espinhos. As informações na sobrecapa da quarta capa, retiradas da parte inicial da narrativa, reforçam esse vínculo com o conto tradicional, dando a impressão de que se trata de uma releitura: "Ela era uma das bruxas da floresta e uma criatura má, relegada a uma vida à margem de tudo, há mil anos. Lançou uma maldição sobre a bebê ao nascer, tal que, quando completasse dezoito anos, a menina furaria o dedo e cairia num sono eterno."

Como podemos observar, a passagem acima faz parte de uma história conhecida, o conto A Bela Adormecida, que, ao ser recontado na narrativa, cria algumas expectativas nos leitores. São as referências que possuímos desse conto que contribuem para o levantamento de algumas hipóteses de leitura. No entanto, a obra de Gaiman e Riddell apresenta uma história diferente, cujo enredo quebra as expectativas do leitor que acredita estar diante de uma releitura do conto de fadas tradicional. Se o leitor for atento e ler as orelhas da sobrecapa, saberá que se trata de uma história bastante diferente, um "conto de fadas tecido com um fio de magia negra, que vira e revira, brilha e reflete. Uma rainha pode se revelar uma heroína, se uma princesa precisar ser salva..." As informações sobre a história na orelha da sobrecapa procuram fisgar o leitor pela curiosidade, alertando-o: "Você pode achar que conhece esta história."

As ilustrações destacam-se na obra. Elas estão presentes nas folhas de guarda, na folha de dedicatória, reinando absolutas em algumas páginas duplas. Nessas páginas, elas são dispostas_em um plano geral, um tipo de enquadramento que, como destaca Linden (2014), apresenta todo o ambiente onde se passa a ação, requerendo um tempo maior de leitura visual. Nas demais páginas, encontramos uma diagramação associativa (LINDEN, 2014), em que texto escrito e ilustração são apresentados na mesma página. Chama a atenção o fato dessas ilustrações serem dispostas em faixas laterais, muito comum nos manuscritos medievais iluminados, denominados glosas. Em A Bela e A Adormecida, Chris Riddell buscou inspiração nesses livros, como ressalta na entrevista concedida à Harper and Collins e vinculada em canal no Youtube:

Acredito que o termo técnico é glosa, na verdade, em manuscritos iluminados, ele perpassa o comprimento da página, e é uma faixa fina e isso permite que você faça o que eu gosto de fazer, que, na verdade, é editar a visão alheia, é como se estivessem olhando através do buraco de caixas de correio virado verticalmente2. (RIDDELL, 2014)

As folhas de guarda são totalmente ilustradas com cadeias de altas montanhas e densas florestas, em preto, sobre o papel branco, com moldura dourada, como na maioria das ilustrações presentes na obra. O enquadramento de cima para baixo em que essas imagens são apresentadas nas folhas de guarda e o fato 
de elas possuírem molduras provocam um certo distanciamento do leitor, que deve mergulhar como observador nesse mundo ficcional, de ambiente insólito e de difícil acesso, com uma lógica certamente diferente da encontrada em seu mundo.

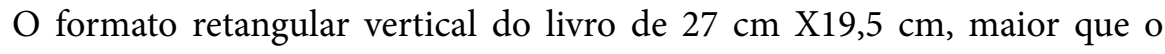
convencional, contribui para que as ilustrações ocupem boa parte das páginas, dando maior visibilidade às páginas duplas, apresentadas no formato paisagem. Como destaca Linden, referindo-se às composições em página dupla: "Um formato vertical não raro se torna um quadrado, ou mesmo horizontal, depois de aberto" (LINDEN, 2014, p. 53).

A tipografia utilizada na obra é um tipo Romano Garaldo, corpo 10 e espacejamento (entrelinhas) 15. Esse tipo possui características das fontes romanas criadas no século XVI, como a Garamond que data de 1531 (NASCIMENTO, 2015 p.39). Destaca-se que, em corpo 10, ela tem sua legibilidade um pouco comprometida, principalmente em se tratando de uma obra que pode ser lida por um público leitor infantil. Na figura a seguir, ampliamos a fonte para facilitar a visualização e sua identificação.
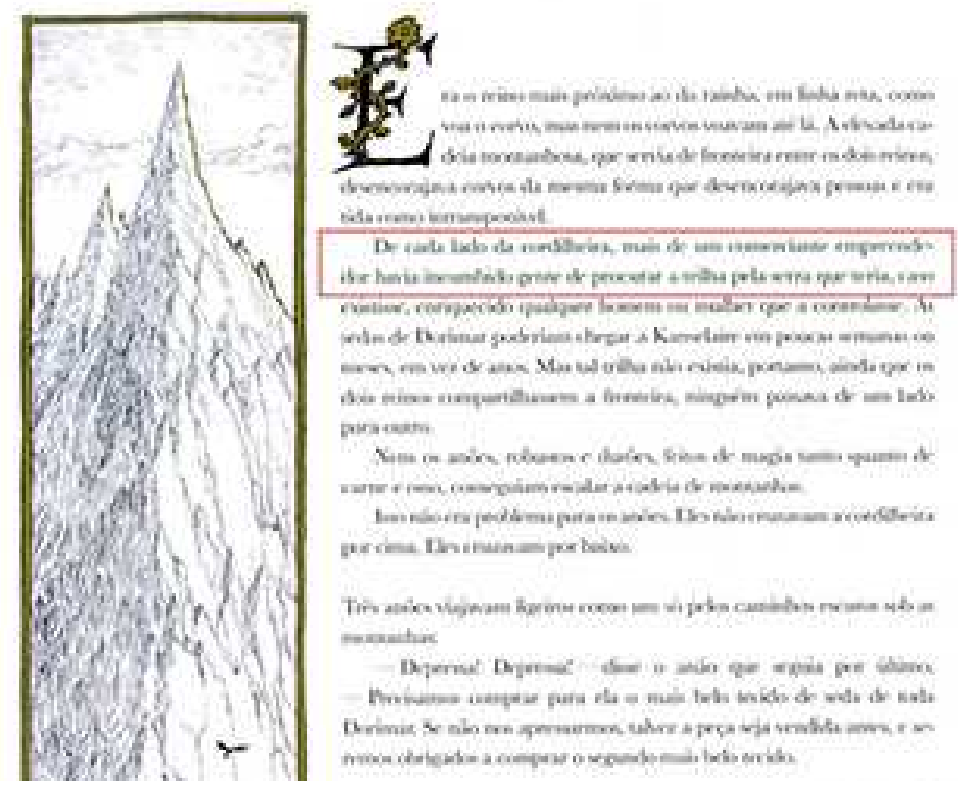

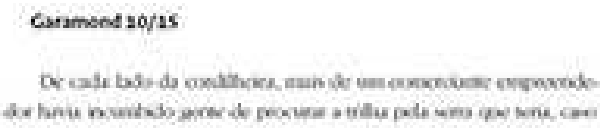

De cada lado da cordilheira, mais dor havia incumbido gente de procurar

Figura 2- Página com fonte destacada

Na figura acima, podemos observar a ilustração disposta em faixa lateral, denominada de glosa, como apontado anteriormente. Destaca-se que, na obra, as ilustrações têm forte influência da estética gótica e são predominantemente em escala de cinza, pendendo para a predominância do branco com linhas pretas e sombreados em cinza, com alguns detalhes em dourado, fazendo referência ao pó ou folha de ouro utilizados nas iluminuras medievais, "em códices de grande importância” (VISALLI e GODOI, 2016, p. 138). Elas também fazem referência aos desenhos oitocentistas de Gustave Doré para os contos de fadas de Perrault, com traçados finos a lápis e riqueza de detalhes. 
Pela grande quantidade de ilustrações presentes na obra, podemos considerá-la uma "narração verbo-visual", segundo a definição proposta por Joseph H. Schwarcz e citada por Nicolajeva e Scott (2011, p. 21). De acordo com Schwarcz, esse tipo de narração é composta pelo texto escrito e pelas ilustrações, que podem desempenhar diferentes funções na narrativa, de acordo com sua relação com as palavras (SCHWARCZ, 1982, p. 11, apud NIKOLAJEVA e SCOTT, 2011, p. 21).

A obra apresenta algumas divisões, ao iniciar determinadas passagens com letras capitulares, letras maiúsculas maiores que as demais, ornamentadas com ramagens e flores, as mesmas que estão presentes ao redor do castelo onde se encontra a jovem adormecida. Essas letras eram muito utilizadas nas iniciais dos títulos dos textos dos manuscritos medievais e eram posteriormente "iluminadas" ("pintadas"). Segundo Visalli e Godoi, no século XII, a iluminura foi influenciada pela arquitetura, escultura e pintura e "um dos elementos de decoração preferidos passou a ser a borda com flores. A grisalha, pintura feita em tons de cinza e preto, também foi uma das novas técnicas aplicadas" (VISALLI e GODOI, 2016, p. 139).

Sendo assim, essas imagens podem ser compreendidas com função ornamental e não apenas de ornamento. Podemos considerar a diferença entre ornamento e ornamental proposta por Bonne: "um motivo geométrico abstrato pode ser apenas um elemento figurativo que decora uma imagem, sendo ornamento, mas pode ser um componente indispensável na construção de uma imagem, como uma inicial, tornando-se ornamental" (BONNE, 1996, apud VISALLI e GODOI, 2016, p. 141). Dessa forma, enquanto o ornamento tem a função estética de decorar, o ornamental está relacionado à construção de sentido da imagem.

A narrativa de Gaiman e Riddell, começando pela extensão (68 páginas), difere-se bastante das versões dos Grimm. Ela é dividida em 16 partes, umas maiores que outras, iniciadas por letras capitulares ornamentadas, o que confere à narrativa uma certa fragmentação que a aproxima mais de uma novela do que de um conto.

Iniciada com "Era um reino..., a obra, narrada em terceira pessoa, apresenta a história de uma valente rainha que, na véspera de seu casamento, é informada por três anões sobre uma terrível maldição que avançava em direção a seu reino: o sono! Pessoas e animais dos reinos vizinhos já tinham sido atingidos. Os anões ficaram sabendo, em uma estalagem, da existência da maldição que faz as pessoas dormirem para sempre. Ela teria sido lançada por uma feiticeira, quase cem anos atrás, sobre um bebê recém-nascido, uma princesa, que, quando completasse dezoito anos, "furaria o dedo e cairia num sono eterno" (GAIMAN e RIDDELL, 2015, p. 16).

Essa passagem é repleta de falas dos personagens que se encontram no bar de uma estalagem, nas quais se observa o uso de expressões típicas da oralidade. Com certo humor, o narrador apresenta a história da maldição como uma "fofoca", um "telefone sem fio", uma vez que cada personagem nomeia a maldição e quem a lançou de uma forma diferente: 
- O que está havendo? - perguntou o mais baixo dos anões.

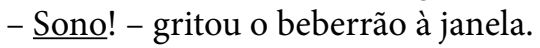

- Praga! - disse uma mulher muito bem-vestida.

- Maldição! - exclamou um funileiro, (...).

- Uma bruxa! - disse o bebum.

- Uma fada má - corrigiu um homem de cara gorda.

- Pelo que ouvi dizer, ela era feiticeira - interveio a garçonete. (...)

- O que eu soube foi que a menina ia morrer, mas outra fada, uma das

boas, reduziu a pena de morte mágica para outra, de sono. Um sono encantado - acrescentou o homem.

- Pois bem - recomeçou o beberrão. - A garota espetou o dedo em alguma coisa. E caiu no sono. E as outras pessoas no castelo, o lorde, a lady, o açougueiro, o padeiro, a leiteira, a dama de companhia, todos dormiram quando a menina adormeceu. Nenhum deles envelheceu nem um dia sequer desde que fecharam os olhos. (GAIMAN e RIDDELL, 2015, p. 15-16, grifos nossos)

Podemos observar que o discurso direto marcado pelo uso de expressões típicas da oralidade confere às histórias contadas o caráter de "causos", de narrativas passadas de pai para filho, de geração para geração, estabelecendo um importante diálogo com a matriz oral dos contos de fadas tradicionais. Apesar de não apresentar nomes, a narrativa reconta a tradicional história da Bela Adormecida. Destaca-se que o nome da maioria dos personagens não é revelado. Gaiman, como bom mitólogo, parece retomar a crença de que nomes são poder e saber os nomes é dar poder a quem os conhece.

Os diálogos dos personagens, no bar de uma estalagem, estão dispostos, na página 16, em uma grande mancha gráfica que ocupa toda a folha, ornada com desenhos de alguns caules de roseiras na parte superior direita e inferior esquerda. Esses elementos, além de decorarem esteticamente a página, como ornamento, fazem referência a uma importante passagem da narrativa, em que a jovem adormecida se encontra em um castelo rodeado de roseiras de grossos caules e espinhos, como é antecipado na capa do livro. Dessa forma, ao serem colocados na passagem narrativa em que a história da Bela Adormecida é contada pelos personagens, podemos afirmar que adquirem também função ornamental, conforme concepção apresentada de Bonne (1996), uma vez que estão relacionados à construção de sentido da imagem.

Essa passagem narrativa é acompanhada, na página da direita (p. 17), por uma ilustração que ocupa toda a folha, com moldura de borda dourada. Destacamos o fato de a ilustração ocupar a página da direita, considerada nobre, por ser apontada como a primeira a que o olhar do leitor se dirige. Isso demonstra o lugar privilegiado da ilustração na narrativa, também contada por Riddell.

A princípio, ilustração e texto escrito apresentam, de forma redundante, a mesma mensagem. Contudo, se considerarmos os detalhes dessa ilustração, somos obrigados a reconhecer a relação de colaboração em que se encontram texto e imagem. Além dos três anões e do estalajadeiro, mais quatro personagens aparecem na cena, três deles olhando para o leitor: um homem aparentemente embriagado com uma caneca na mão, uma mulher de longas tranças, vestido deco- 
tado e olhar assustado, segurando um jarro, um homem gordo de rosto redondo e um homem, de nariz e boca afilados, com uma gola que faz lembrar as roupas dos nobres. Apesar de o texto escrito fazer referência a um bêbado e a um homem de cara gorda (GAIMAN e RIDDELL, 2015, p. 16), que podem ser associados aos personagens da ilustração, esta, por meio da riqueza de detalhes, extrapola o texto escrito. Sendo assim, entre as funções do texto e imagem, podemos afirmar que a ilustração apresenta não apenas a função de repetição ou a de seleção da mensagem do texto escrito, mas também a de amplificação, uma vez que amplia a mensagem do texto escrito "trazendo um discurso suplementar ou sugerindo uma interpretação" (LINDEN, 2011, p. 125).

Diante do que foi contado aos anões, o leitor, levado pela imagem da jovem na capa do livro e pelo título que faz referência a duas personagens (Bela e Adormecida), pode criar algumas expectativas em relação ao desenrolar da história. Uma das possíveis hipóteses de leitura é associar a Adormecida à jovem amaldiçoada por uma feiticeira e a rainha à Bela. Algumas características da rainha, como cabelos negros e pele branca, fazem referência à Branca de Neve. Apesar de não ter seu nome revelado, ela faz algumas afirmações, ao longo da narrativa, que permitem ao leitor considerar essa associação, como o fato de ter tido uma madrasta má e ter dormido um ano inteiro em um caixão de vidro (GAIMAN e RIDDELL, 2015, p. 56).

Essa associação também é reforçada pelo fato de a rainha estar acompanhada por anões, com os quais viveu "quando era pouco mais que uma criança" (GAIMAN e RIDDELL, 2015, p. 23). Contudo, em vez de sete, como no conto tradicional, a narrativa apresenta três. Esse número, assim como o sete, possui uma importante carga simbólica. Segundo Mesquita, o três representa "a síntese perfeita entre o homem, o céu e a terra" (MESQUITA, 2012, p. 4). Nos contos de fadas, ele costuma aparecer "associado aos diferentes momentos do desenvolvimento humano e da consciência" (MESQUITA, 2012, p. 4), sempre com um caráter mágico e transcendente.

Nas ilustrações da obra analisada, os anões apresentam uma espécie de chapéu-castiçal, no qual eles utilizam uma vela para iluminar o interior das montanhas por onde andam. Esse objeto é apresentado em dourado, mesma cor utilizada para a borda da moldura presente na maioria das ilustrações, contrastando-se com a cor preta dos demais desenhos.

A imagem das três chamas das velas acesas apresenta um forte simbolismo, podendo ser relacionada a um tipo de intervenção divina, a algo transcendental. É interessante observar que nesta história os anões são apresentados como seres mágicos que percorrem o interior das montanhas. Segundo Corso e Corso, esses seres, muito presentes no folclore europeu,

são sempre criaturas da terra, ou melhor, das entranhas da terra. São mineradores incansáveis e detentores dos segredos e tesouros do interior das montanhas. Geralmente, são representados como adultos em miniatura, usam longas barbas, são avarentos e não muito amistosos. (CORSO e CORSO, 2006, 
p. 81)

Gaiman recupera essa origem dos anões, que iniciam a narrativa viajando "pelos caminhos escuros sob as montanhas" (GAIMAN e RIDDELL, 2015, p. 10). De forma complementar, Riddell os apresenta sempre com o chapéu-castiçal preso à cabeça ou em suas mãos, representando simbolicamente o caráter transcendental dessas criaturas.

Acompanhada pelos três anões, a protagonista desta história parte para salvar seu reino, enfrentando a maldição desconhecida. Observamos, assim, um contraponto em relação à narrativa tradicional da Branca de Neve, que é salva da maldição ao ser acordada do sono profundo por um príncipe. Enquanto Branca de Neve tinha no casamento sua salvação, o que lhe garantiria o final "feliz para sempre", a rainha desta história sente-se receosa e triste com esse destino.

A passagem narrativa que apresenta essa personagem é iniciada por uma detalhada ilustração em página dupla (Figura 3, 2015, p. 12-13). O fato dessa imagem vir antes do texto escrito e ocupar um lugar de destaque no livro nos permite considerá-la, nessa parte da obra, como "instância primária", de acordo com a caracterização de Linden (2011). Nessa passagem, a ilustração é "lida" antes do texto escrito que, apresentado posteriormente, complementa a mensagem transmitida por ela.

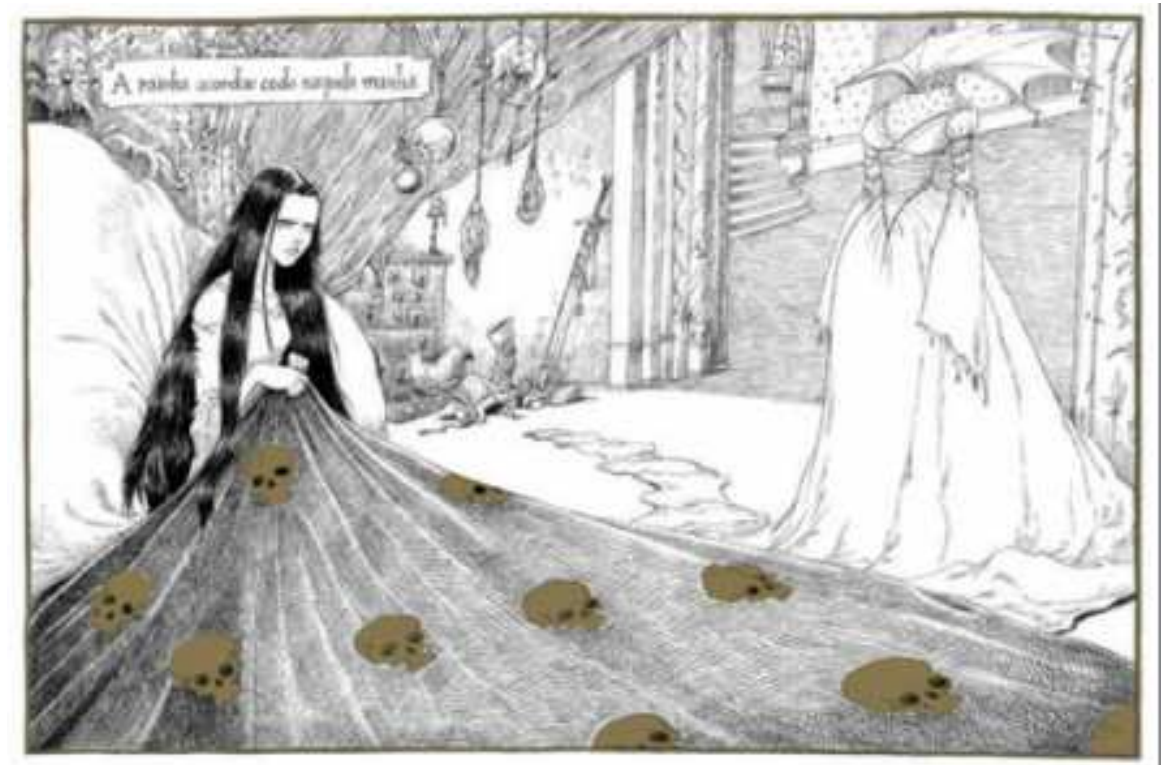

Figura 3- Rainha acordando

Observa-se na ilustração acima a presença de um pequeno texto em uma cai$\mathrm{xa}$, na parte superior esquerda da página dupla: "A rainha acordou cedo naquela manhã." Esse texto é escrito em letra dourada e reproduz a primeira frase da passagem que vem na página seguinte, antecipando, assim, seu conteúdo. $\mathrm{O}$ fato de $\mathrm{o}$ texto encontrar-se em uma caixa nos remete à técnica narrativa utilizada nas histórias em quadrinhos, cuja voz do narrador costuma aparecer em caixas denomina- 
das de recordatários. No caso do livro em questão, trata-se, como já destacado, de uma repetição de frase, referente ao discurso do narrador observador.

Os crânios, em dourado, presentes na colcha da rainha destacam-se na imagem. Como símbolo da mortalidade na cultura ocidental (LEXIKON, 1990), representa a transitoriedade da vida, assim como transformação, início de um novo ciclo. Representando ainda a morte, o macabro, os crânios podem ser associados ao gótico. $\mathrm{O}$ manequim sem cabeça presente no quarto, com um vestido de gola vampiresca, complementa o ambiente gótico sugerido pela ilustração. A expressão do rosto da personagem evidencia sua tristeza, cujo motivo é contado no texto escrito da página seguinte:

A rainha acordou cedo naquela manhã.

- Em uma semana - pensou em voz alta. - Em uma semana, estarei casada.

Isso parecia ao mesmo tempo improvável e extremamente definitivo. Ela ficou se perguntando como se sentiria na condição de esposa. Seria o fim de sua vida, concluiu, se a vida fosse um tempo de escolhas. Em uma semana não teria mais o que escolher. Reinaria sobre seu povo. Teria filhos. Talvez morresse durante o parto, talvez de velhice, ou em batalha. Mas o caminho para a sua morte, a cada batida de seu coração, seria inevitável. Ela podia ouvir os carpinteiros no prado ao pé do castelo fazendo os bancos que permitiriam seu povo assistir ao casamento. Cada golpe de martelo soava como a batida de um coração. (GAIMAN e RIDDELL, 2015, p. 14)

Essa parte da narrativa, muito pequena em extensão, apresenta a rainha, com longos cabelos negros, refletindo sobre as mudanças pelas quais estava prestes a passar em sua vida com a aproximação de seu casamento e do que viria depois (Figura 4).

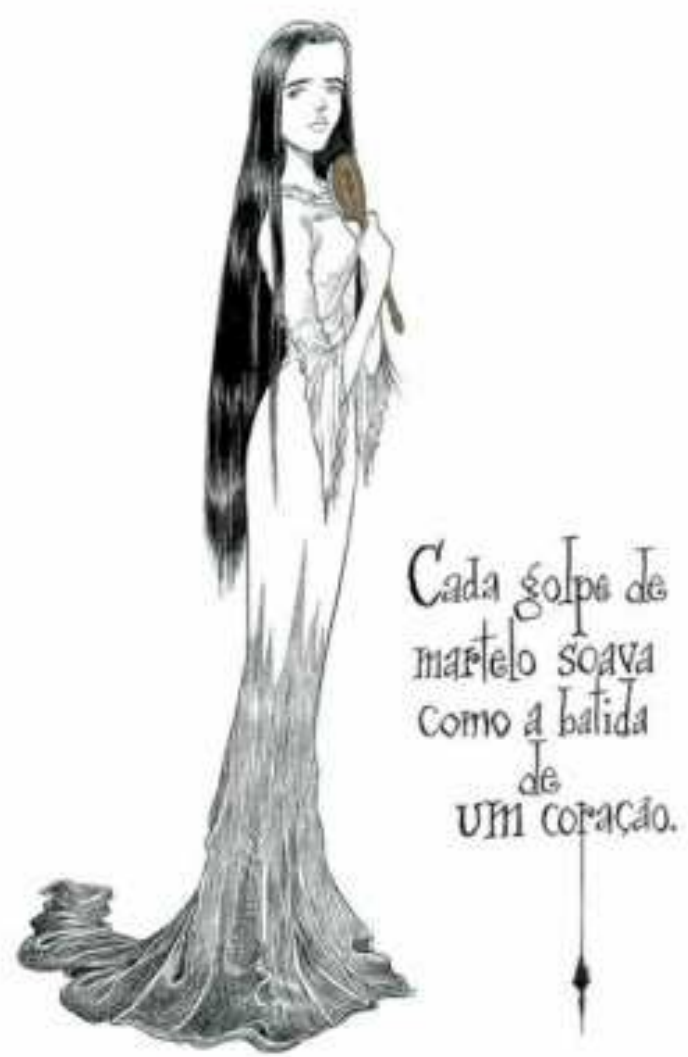


Figura 4 - Rainha se arrumando, pensativa

O texto escrito, em letra dourada, que acompanha a ilustração, reproduz a última frase do bloco de texto que o antecede, reforçando, assim, seu conteúdo. Ao longo do livro, observamos outras pequenas frases como essa, em letra dourada, de tipografia diferente da utilizada no texto escrito, que reproduzem alguma passagem da história, reforçando o diálogo entre ela e a ilustração. Em entrevista, Riddell informa que a tipografia utilizada nessas passagens, em dourado, é de sua autoria. Ela aparece em diversas caricaturas e poesias ilustradas por ele, veiculadas em sua página da Web. Para Riddell algumas ilustrações presentes na obra "pediam" um texto em destaque e neles ele desenhou um fuso pendendo de alguma letra do texto "ilustrado". Os números das páginas, na parte inferior central, também são ilustrados com teias ou fusos.

É importante destacar que, em inglês, o título The Sleeper and the Spindle faz referência ao fuso. Esse objeto, tão importante no conto de fadas "A Bela Adormecida", é hoje um artefato praticamente desconhecido e sua imagem em destaque em várias páginas chama a atenção do leitor para esse objeto. Além disso, o fuso adquire uma funcionalidade ornamental, na medida em que desempenha um importante papel na história, como discutimos anteriormente. Sobre o conto tradicional "A Bela Adormecida", Bettelheim destaca que

a maldição se centraliza no fuso, uma palavra que em inglês veio representar as mulheres em geral. Embora o mesmo não seja verdadeiro para o termo francês de fuso (Perrault) ou alemão (Grimm), até recentemente ficar a tecer eram consideradas ocupações caracteristicamente "femininas". (BETTELHEIM, 1980, p. 272)

Como destaca Corso e Corso, "a roca (fuso) era um objeto absolutamente indispensável do cotidiano das mulheres; depois de cozinhar, tecer era a ocupação feminina por excelência" (CORSO e CORSO, 2006, p. 88). Na narrativa de Gaiman e Riddell, podemos entender o fuso ainda como o objeto mágico que costuma aparecer nos contos de fadas.

Bettelheim, em sua análise psicanalítica dos contos de fadas, destaca que eles encaram "o mundo e o que sucede nele de forma não objetiva, mas sob a perspectiva do herói, que é sempre uma pessoa em desenvolvimento" (BETTELHEIM, 1980, p. 242). Para ele, em "alguns contos de fadas o herói tem de procurar, viajar e sofrer vários anos de existência solitária antes de estar preparado para encontrar, salvar e reunir-se a outra pessoa numa relação que dá significado permanente às duas vidas" (BETTELHEIM, 1980, p. 241). Sobre "Branca de Neve", ele afirma que "são os anos que passa com os anões que representam o período de dificuldades, de elaboração dos problemas, seu período de crescimento" (BETTELHEIM, 1980, p. 241).

A heroína desta história já passou por esse momento, como ela mesma afirma na narrativa (GAIMAN e RIDDELL, 2015, p. 56), e, no entanto, parece estar diante de um novo dilema existencial. Entre casar-se e partir a cavalo estrada afo- 
ra, não restam dúvidas à rainha: ela adia o casamento e, pegando sua espada, cavalga em direção ao leste, para acabar com a maldição. Sendo assim, esse período de aventura que passa com os anões pode ser compreendido como um segundo período de amadurecimento, de descoberta de si. O resultado dessa jornada, contudo, diferentemente do que é analisado por Bettelheim nos contos tradicionais, não é o encontro com o ser amado, como será abordado mais adiante.

Em sua jornada para salvar o reino, a rainha, acompanhada dos anões, enfrenta espaços insólitos, encontrando pelo caminho uma população de pessoas adormecidas. As ilustrações assumem um importante papel narrativo, ao apresentar seres e ambientes não relatados no texto escrito. Dentre elas, encontra-se a ilustração que ocupa toda a página 19, apresentando em primeiro plano uma tiradora de leite adormecida, encostada à vaca, com o balde de leite repleto de cogumelos, representando o tempo decorrido. Essa ilustração foi elogiada por Gaiman em entrevista, já citada neste artigo, em que o escritor ressalta a experiência diferenciada de leitura da narrativa propiciada pelas ilustrações, que acrescentam personagens e cenas que enriquecem a obra.

Como exemplo, destaca-se ainda a estranha criatura sonolenta, de tamanho monstruoso e aspecto pré-histórico, que aparece em dois momentos da narrativa, sem ser mencionada no texto escrito: logo na segunda página (Figura 5, p. 11), complementando a passagem textual que inicia a narrativa, em que os anões caminham sob as montanhas, e no início da jornada da rainha e dos
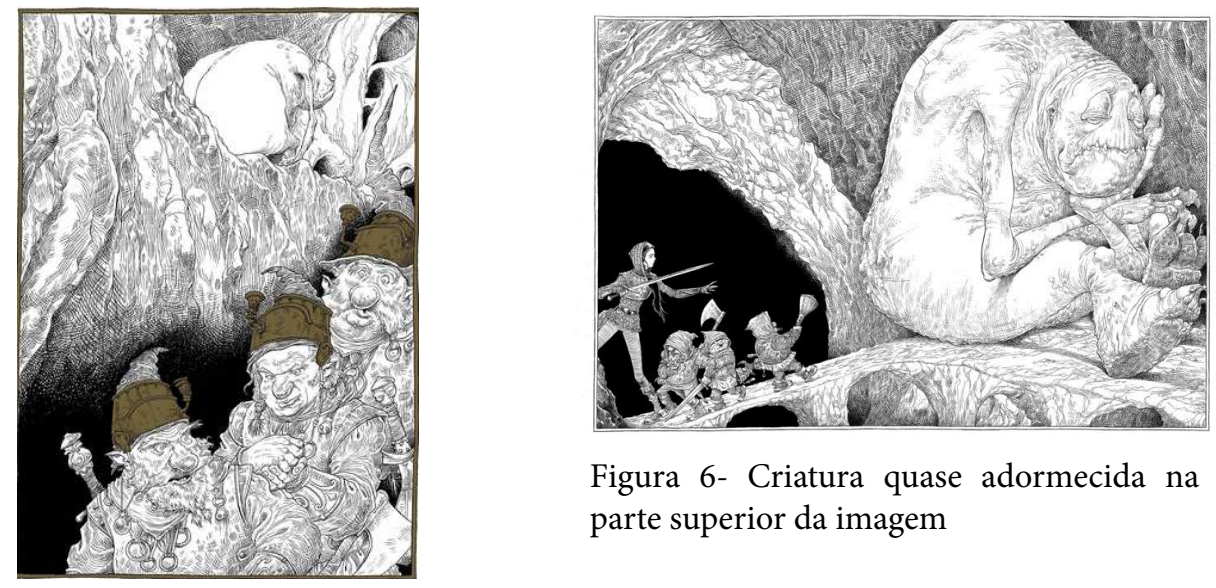

Figura 6- Criatura quase adormecida na parte superior da imagem

anões (Figura 6, p. 24-25).

Figura 5- Criatura locomovendo-se,

Na primeira aparição, a criatura parece caminhar lentamente no interior das montanhas, já na segunda, em ilustração que ocupa página dupla, ela se encontra quase adormecida, parecendo ter sido atingida pela maldição do sono.

Podemos observar as diferentes relações entre ilustração e texto escrito no decorrer da narrativa. Na maioria das vezes, a ilustração reforça o que é contado no texto, acrescentando a ele detalhes enriquecedores. Algumas ilustrações, contudo, ampliam a narrativa, por meio da presença de novos personagens e cená- 
rios impactantes.

Entre esses cenários, destaca-se a imagem das pessoas adormecidas envolvidas em teias de aranha, o que as torna semelhantes a seres monstruosos, mumificados.

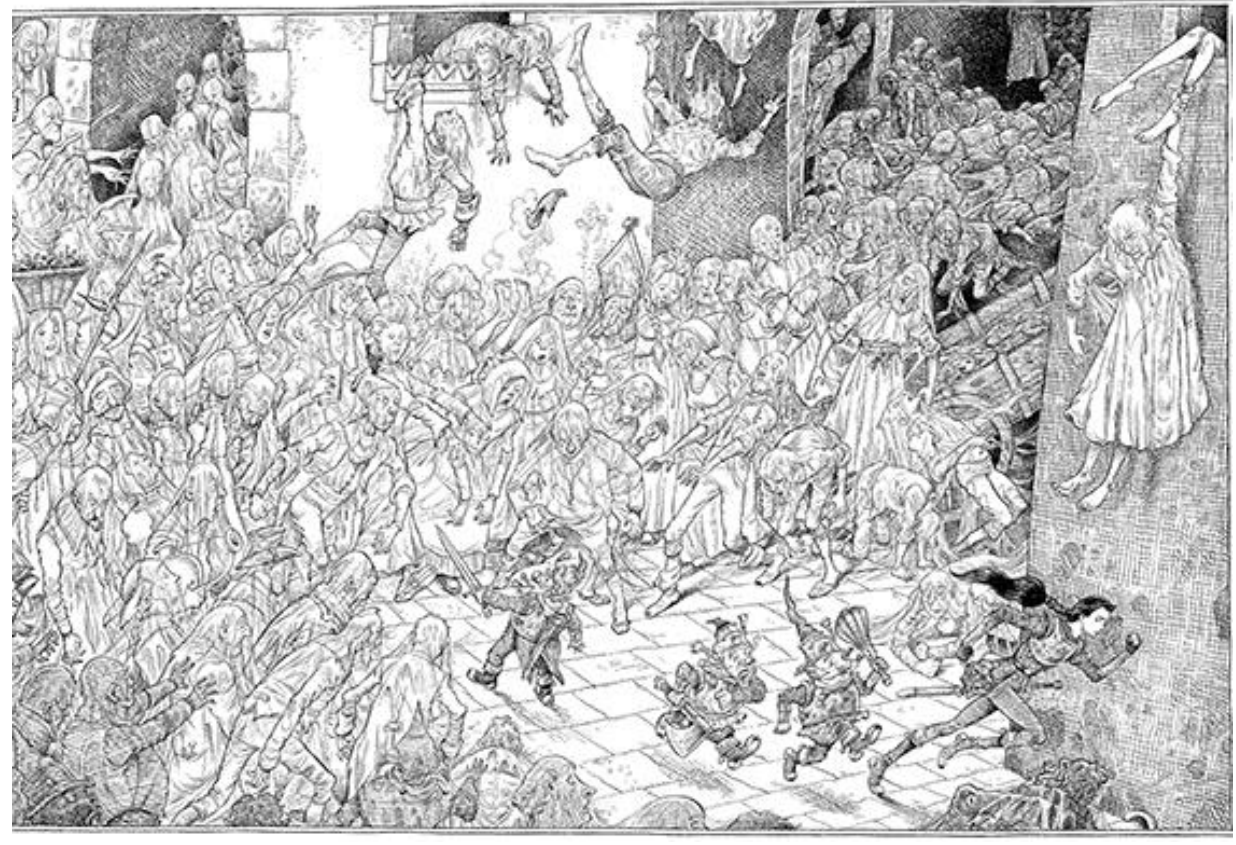

Figura 7 - Pessoas adormecidas, cobertas por teias, andando pelo reino

Como zumbis, "os adormecidos seguiam em direção aos anões e à rainha" (GAIMAN e RIDDELL, 2015, p. 35), que entram na cidade em busca do castelo. As teias também representam o tempo, que não para de correr. Como observa um dos anões: “- As tecedeiras não estão dormindo" (GAIMAN e RIDDELL, 2015, p. 26) -, referindo-se às aranhas que não paravam de trabalhar, o que traz para a narrativa uma grande carga simbólica. Dentre os diversos significados associados à aranha, está o de tecelã do destino. Na mitologia grega, temos a deusa Atena e na mitologia nórdica, sobre a qual Gaiman escreveu um livro3 (2017), temos as Nornas, que tecem o destino dos homens e dos deuses.

Ao chegar ao castelo, na Floresta de Acaire, rodeado por trepadeiras repletas de espinhos e de caveiras, a heroína, como o príncipe do conto tradicional, corta com sua espada os grossos espinhos e adentra no espaço do castelo amaldiçoado. Para sua surpresa, dentre as inúmeras pessoas adormecidas que vagavam como sonâmbulos pelo castelo, a rainha e os anões se deparam com um ser desperto: uma velha senhora, apoiada em uma bengala. Ignorando-a, a rainha sobe até a torre mais alta e puxa o cortinado da cama, encontrando uma jovem adormecida, a mesma representada na capa do livro.

O rosto da adormecida os encarava cegamente.

- Então foi aqui que tudo começou - disse um dos homenzinhos.

- No aniversário dela - complementou outro.- Bem - disse o terceiro Alguém precisa fazer as honras.- Eu faço - disse a rainha, baixinho. 
Ela aproximou o rosto da mulher adormecida. Seus lábios cor de carmim tocaram a boca cor-de-rosa da outra num beijo prolongado e intenso. (GAIMAN e RIDDELL, 2015, p. 49)

Essa passagem textual é reforçada, em uma relação de redundância, por uma ilustração em página dupla que vem a seguir.

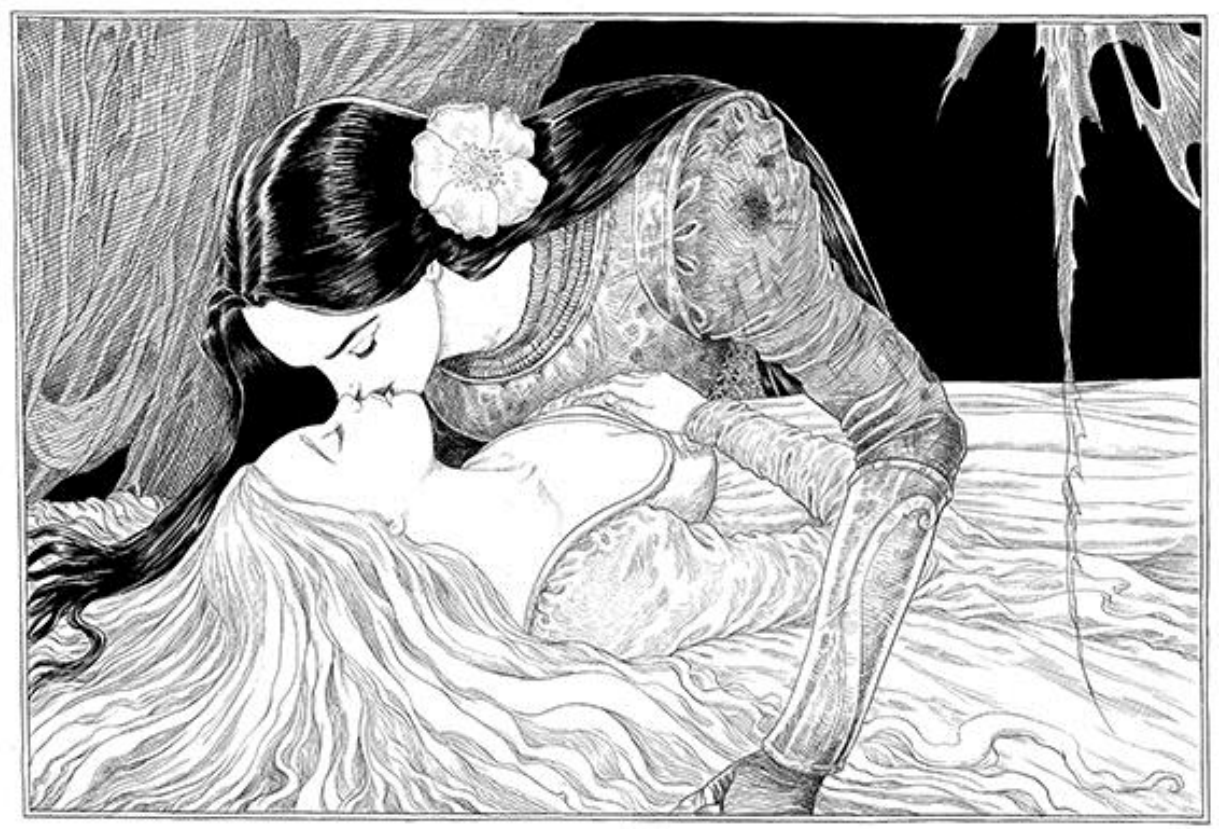

Figura 8 - A adormecida é beijada pela rainha

$\mathrm{O}$ beijo entre as duas personagens pode causar uma quebra de expectativa no leitor, se a história for comparada à sua matriz textual: o conto de fadas "A Bela Adormecida”, em que a Bela é acordada por um príncipe. Portanto, podemos observar que se trata de um evento "anti-esperado", diferente do meramente inesperado. O emprego do "anti-esperado" é destacado por Jackson, Coats e McGillis (2009, p. 76) como parte da temática gótica.

Enquanto no conto tradicional o beijo representa o clímax da narrativa, que caminha para um final feliz, na obra em questão, ao despertar a suposta princesa, ele traz uma importante revelação, mostrando ao leitor que nem tudo o que vemos é o que parece ser. A jovem recém- acordada se apresenta como a feiticeira, responsável por espalhar a maldição do sono. A princesa, vítima da maldição, revela-se como sendo a velha senhora, a única acordada no reino. E ainda, quebrando possíveis expectativas dos leitores, a destemida heroína da história não é quem salva o dia, mas, sim, a velha princesa que espeta a bruxa com o fuso, o que faz com que ela morra e o feitiço se quebre. 


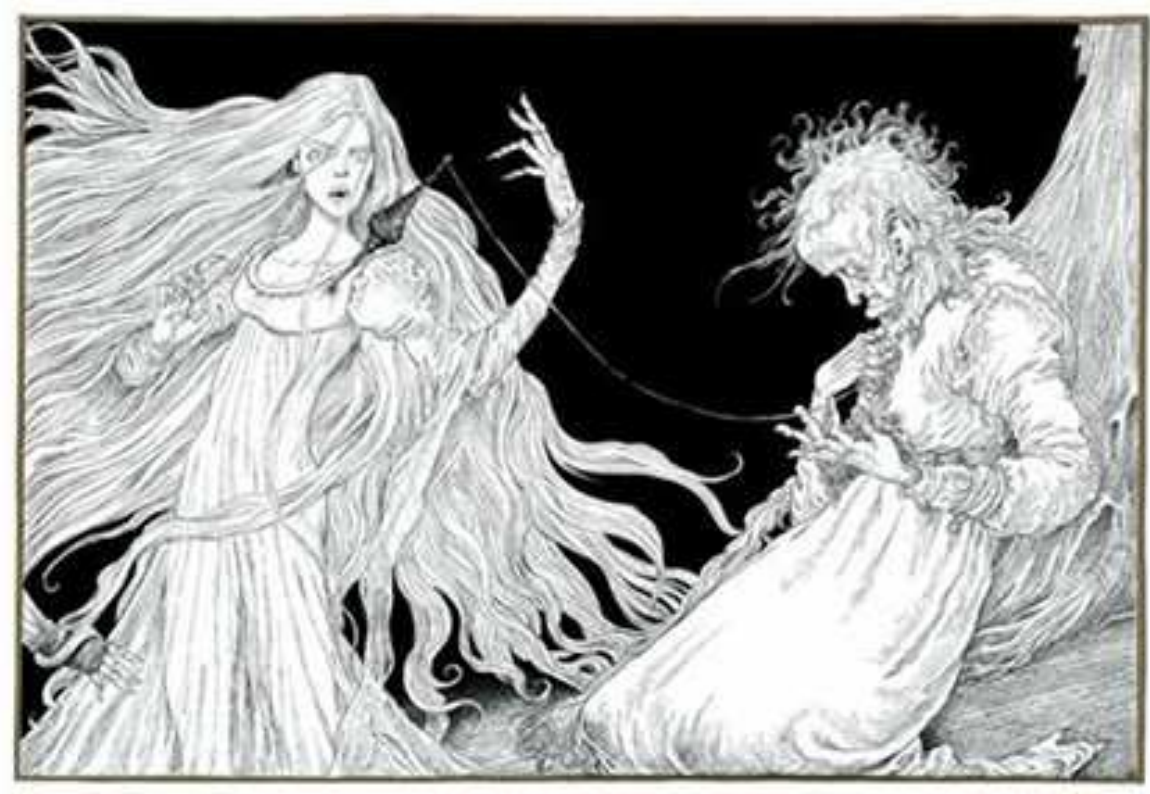

Figura 9 - A bruxa é atingida pela velha princesa

Segundo Corso e Corso (2006, p. 86), das "princesas dos contos de fadas, a Bela Adormecida é a mais passiva, a começar por seu nome. Sua característica principal é a beleza inerte (...)." Já na obra em questão, é a velha princesa que salva o reino, enfiando o fuso (roca) no peito da bruxa. Podemos observar que a narrativa também é contada pelas ilustrações, que acrescenta novas possibilidades de leitura. Na imagem acima (Figura 8, p. 60-61), a expressão de pânico da bruxa, em corpo jovem, contrasta-se com a expressão de tranquilidade da velha princesa. Esta, com um olhar triste, voltado para baixo, segura e observa o fio que acompanha o fuso, que representa sua vida, como já mencionado em passagem anterior: “- Isto era minha vida - falou.- Este fio era minha vida..." (GAIMAN e RIDDELL, 2015, p. 59).

A inexorabilidade do destino tematizada no conto tradicional A Bela Adormecida é retomada e questionada na obra de Gaiman e Riddell. A princesa não dependeu de nenhum príncipe para lhe salvar da maldição e, aliás, uma adormecida às avessas, era a única desperta no castelo. Da mesma forma, a rainha não vê seu casamento como "um final feliz", um destino inevitável. Em vez de voltar para sua casa, viajando em direção ao oeste, ela segue firme, com os anões, para o leste: "Existem escolhas, pensou ela quando já estava sentada ali por algum tempo. Existem sempre escolhas. Ela fez uma” (GAIMAN e RIDDELL, 2015, p. 66).

\section{Considerações finais}

Na obra de Gaiman e Riddell, a narrativa é construída por meio do jogo entre tradição e inovação. Os contos de fadas tradicionais não são apenas o ponto de partida para a história contada; eles apresentam personagens, acontecimentos, valores e elementos simbólicos arquetípicos que são retomados na obra, seja por afirmação ou questionamento. A história é marcada pela quebra de expectativas que, para ser realizada, requer que seus leitores conheçam os contos de fadas tradicionais. 
Muitas características presentes em A Bela e a Adormecida podem ser associadas ao gótico, como o espaço insólito (o castelo/prisão), o retorno a tempos medievais (pela própria referência aos contos de fadas), o horror, o terror e o medo. Jackson, Coats e McGillis destacam, em relação às obras de Gaiman em geral, que elas apresentam o gótico bem-feito e que ele pode ter uma importante função para as crianças, dando \expressão concreta aos processos psíquicos abstratos, mantendo fascinações escuras e medos assustadores onde as crianças pos-

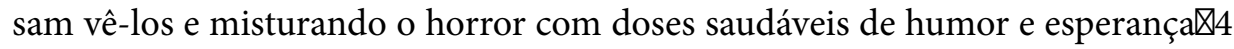
(JACKSON, COATS e MCGILLIS, 2009, p. 88, tradução nossa). Esses autores chamam a atenção para o fato de os vilões serem realmente maus e desagradáveis e as heroínas serem corajosas e firmes para vencê-los.

As ilustrações destacam-se na obra, pela grande quantidade, pela beleza estética e pelo importante papel que exercem na construção da narrativa. Elas relacionam-se de diferentes formas com o texto escrito ao longo do livro. Na maioria das vezes, reforçam o que é contado no texto, acrescentando a ele detalhes enriquecedores. Algumas ilustrações, contudo, ampliam a narrativa, por meio da presença de novos personagens e cenários impactantes. Portanto, entre os tipos de relações entre texto e imagem apontados por Linden (2011), predominam na obra os de colaboração e, entre as funções da ilustração, encontram-se não apenas as de repetição e de seleção da mensagem do texto escrito, mas também a de amplificação, uma vez que as ilustrações acrescentam novos elementos à história.

A diagramação, como importante elemento do projeto gráfico de um livro, também deve ser considerada para a construção bem-sucedida da narrativa. É por meio dela que se define o espaço a ser ocupado pelo texto escrito e pelas imagens, o que influencia diretamente a relação entre eles. A colocação das ilustrações em páginas duplas emolduradas, em faixas laterais, associadas ao texto escrito de diversas formas, como demonstrado neste artigo, é resultado de decisões referentes ao projeto gráfico do livro. Dele também fazem parte a elaborada capa e a sobrecapa em papel vegetal, que, como apresentamos, contribuem para a construção de sentido da narrativa, antecipando de forma criativa importantes elementos da história.

Podemos afirmar que a narrativa é contada não apenas pelo texto escrito, mas também pelas ilustrações e pelo projeto gráfico, no qual o ilustrador teve grande participação. Como destacamos, Riddell teve liberdade criativa para acrescentar, nas ilustrações, sua interpretação da história, podendo ser considerado, assim como Gaiman, autor da narrativa, uma vez que ela também é contada pelas ilustrações. O diálogo entre escritor e ilustrador e a liberdade que este teve para apresentar seu ponto de vista foram fundamentais para a construção bemsucedida da obra.

\section{Notes}

1. I think of a heavily illustrated book like this is simply an experience that you wouldn't have if you were just exposed to the text. You would never get to see things like the mushrooms growing in the milkmaids pail (...) (GAIMAN, 2014). 
2. I think the technical term is a glossary actually in illuminated manuscripts it runs the length of the page but it's a thin strip and it allows you to do what I enjoy doing which is actually editing ones view; it's as if I'm looking through a letterbox that's turned on its side (RIDDELL, 2014).

3. GAIMAN, Neil. Mitologia nórdica. Rio de Janeiro: Intrínseca, 2017.

4. "concrete expression to abstract psychic processes, keeping dark fascinations and haunting fears where children can see them, and mingling the horror with healthy doses of humour and hope." (JACKSON, COATS e MCGILLIS, 2009, p. 88).

\section{Referências}

ADG. Associação dos Designers Gráficos do Brasil. $A B C$ da $A D G$ - glossário de temas e verbetes utilizados em design gráfico. São Paulo: ADG, 2012.

BETTELHEIM, Bruno. A psicanálise dos contos de fadas. Trad. Arlete Caetano. Rio de Janeiro: Paz e Terra, 1980.

BONNE, Jean-Claude. Formes et fonction de lornamental dans l'arte médiéval (VIII e -XII e siècle). Le modèle insulaire. In: BASCHET, Jérôme; SCHMITT, JeanClaude. LIMAGE: Fonctions et usages des images dans l'Ocident médiéval. Paris: Le Léopard d'Or, 1996, p. 207-250. v. 5.

COELHO, Nelly Novaes. Panorama histórico da literatura infantil/juvenil. 4.ed. São Paulo: Ática, 1991.

O conto de fadas: símbolos - mitos - arquétipos. 4.ed. São Paulo: Paulinas, 2012.

CORSO, Diana Lichtenstein; CORSO, Mário. Fadas no divã. Porto Alegre: ArtMed, 2006.

EISNER, Will. Quadrinhos e arte sequencial. São Paulo: Martins Fontes, 1999.

FRANZ, Marie-Louise Von. A Interpretação dos Contos de Fada. $3^{\text {a }}$ ed. Trad. Maria Elci Spaccaquerque Barbosa. São Paulo: Paulus, 1990.

GAIMAN, Neil. A bela e a adormecida. Ilustração Chris Riddell; trad. Renata Pettengill. Rio de Janeiro: Rocco Jovens Leitores, 2015.

GIGLIO, Zula Garcia (org). Contos Maravilhosos: Expressão do Desenvolvimento Humano. Campinas: NEP/UNICAMP, 1991.

GRIMM, Jacob, GRIMM, Wilhelm. Contos maravilhosos infantis e domésticos. Trad. Christine Röhrig. São Paulo: Cosac Naify, 2012.

JACKSON, Anna, COATS, Karen e MCGILLIS, Roderick. The Gothic in Children's Literature: Haunting the Borders. New York NY, Routledge, 2009.

LEXIKON, Herder. Dicionário de símbolos. Trad. Erlon José Paschoal. São Paulo: Cultrix, 1997.

LINDEN, Sophie Van der. Para ler o livro ilustrado. Trad. Dorothée de Bruchard. São Paulo: Cosac Naify, 2011.

MESQUITA, Armindo Teixeira. A simbologia dos números três e sete em contos maravilhosos in Álabe. Revista de Investigación sobre Lectura y Escritura. España: Red de Universidades Lectoras y Universidad de Almería, n 6, dic. 2012, p.1-14. ISSN: 2171-9624. Disponível em: <www.revistaalabe.com>. Acesso em: out. 2017.

MORAES, Odilon. O projeto gráfico do livro infantil e juvenil. In OLIVEIRA, Ieda de. (Org.) O que é qualidade em ilustração no livro infantil e juvenil: com a palavra o ilustrador. São Paulo: DCL, 2008, p.49-59. 
NASCIMENTO, Luiz Augusto. O design do livro didático de alfabetização: tipografia e legibilidade. Saarbrücken, Alemanha: Novas Edições Acadêmicas, 2015.

NIKOLAJEVA, Maria e SCOTT, Carole. Livro ilustrado: palavras e imagens. Trad. Cid Knipel. São Paulo: Cosac Naify, 2011.

RAMOS, Graça. A imagem nos livros infantis: caminhos para ler o texto visual. Belo Horizonte: Autêntica, 2013.

VISALLI, Angelita Marques e GODOI, Pâmela Wanessa. Estudos sobre imagens medievais: o caso das iluminuras. In Diálogos - Revista do Departamento de História e do Programa de Pós-Graduação em História, vol. 20, núm. 3, 2016, p. 129-144. Universidade Estadual de Maringá, Maringá, Brasil.

VON FRANZ, Marie-Louise. A interpretação dos contos de fadas. São Paulo: Paulus, 1990.

\section{Vídeos e sites}

https://www.theguardian.com/childrens-books-site/gallery/2014/nov/09/chris-riddell-the-sleeper-and-the-spindle-gallery-neil-gaiman acessado em 13 de novembro de 2017.

https://bloomsbury.com/uk/the-sleeper-and-the-spindle-9781408878422/ acessado em 13 de novembro de 2017.

https://www.youtube.com/watch?v=76p5i861rds acessado em 13 de novembro de 2017.

https://www.youtube.com/watch?v=U9e1LpbXevg acessado em 13 de novembro de 2017.

https://www.youtube.com/watch?v=Y1yvbXJDz1c\&t=42s acessado em 13 de novembro de 2017. 